\title{
Impact of the Covid-19 Pandemic on Orthopaedic and Trauma Surgery - A Systematic Review of the Current Literature
}

\author{
PHILIPP BLUM $^{1}$, DAVID PUTZER $^{2}$, MICHAEL C. LIEBENSTEINER $^{1}$ and DIETMAR DAMMERER ${ }^{1}$ \\ ${ }^{1}$ Department of Orthopaedics and Traumatology, Medical University of Innsbruck, Innsbruck, Austria; \\ ${ }^{2}$ Department of Experimental Orthopaedics, Medical University of Innsbruck, Innsbruck, Austria
}

\begin{abstract}
Background/Aim: The Coronavirus disease 2019 (COVID-19) has led to significant disruptions in various medical specialties. We herein aimed to provide a systematic review of the published literature on the impact by the Covid-19 pandemic on orthopaedic and traumatological care by focusing on the number of clinical visits, surgeries and reasons for consultation. Materials and Methods: The published literature was reviewed using PubMed. Of 349 studies published between December 1, 2019 and October 1, 2020, 36 original articles met the inclusion criteria. Articles were selected on the basis of the PRISMA guidelines. October 1, 2020 was used as the concluding date of publication. Results: The number of elective visits declined by $50.0 \%$ to $74.0 \%$. The number of emergency and trauma visits showed a decrease of $37.7 \%$ to $74.2 \%$. Trauma surgery decreased by $21.2 \%$ to $66.7 \%$ and elective surgeries by $33.3 \%$ to $100 \%$. Conclusion: Orthopaedic and trauma surgery is clearly influenced by the pandemic. It will be important to maintain treatment and surgical care of patients in order to avoid negative effects on treatment progress.
\end{abstract}

Since the first cases of a novel respiratory disease occurred in Wuhan, China in December 2019, Coronavirus disease 2019 (Covid-19) has spread worldwide (1). While the World Health Organization (WHO) classified Covid-19 as a public health emergency on January 30, 2020, it changed the classification on March 11, 2020 and rated Covid-19 as a

This article is freely accessible online.

Correspondence to: Philipp Blum, Department of Orthopaedics and Traumatology, Medical University of Innsbruck, Anichstrasse 35, 6020 Innsbruck, Austria. Tel: +43 51250422691, e-mail: philippblum1@gmx.de

Key Words: Covid-19, orthopaedics, traumatology, recommendations, pandemic, review. pandemic (2). Since November 29, 2020, 61,866,635 people have been infected with the novel coronavirus. In addition, $1,448,990$ infected people have died (3).

The Covid-19 pandemic and associated lockdowns have changed our daily lives dramatically, not only by exerting a major impact on our activities and the economy, but especially on our healthcare systems. The large number of infected persons in certain parts of the world has caused hospitals to restructure their departments in order to increase treatment capacity for Covid-19 patients. Angelico et al. reported a $25 \%$ decrease in organ transplantations in response to available intensive care unit capacity in the first four weeks in Italy, which was one of the first European countries to deal with the Covid-19 pandemic (4). Furthermore, fewer cases of colorectal carcinoma were diagnosed in Spain during the state of emergency compared to the previous year, probably due to a restriction in endoscopic and surgical procedures and a reduced number of cancer prevention screenings (5). In addition to these medical disciplines, the Covid-19 pandemic also affected orthopaedics and traumatology, where elective surgeries were postponed and nonurgent consultations cancelled to minimize the risk of infection for patients and medical staff $(6,7)$.

The aim of this systematic literature review was to provide an overview of the impact of the Covid-19 pandemic on orthopaedic and traumatologic care by comparing previously published reports from different countries, especially focusing on the number of clinical visits, surgeries and reasons for consultation.

\section{Material and Methods}

A comprehensive literature search was conducted covering a period from December 1, 2019 to October 1, 2020 to include all possible matching articles since the appearance of the new coronavirus. PubMed served as the primary database for the literature search. The search was performed using the following search string: "orthopaedics" OR "orthopedics" OR "traumatology" AND "covid-19" OR "sars-cov-2" OR "coronavirus". The review was 

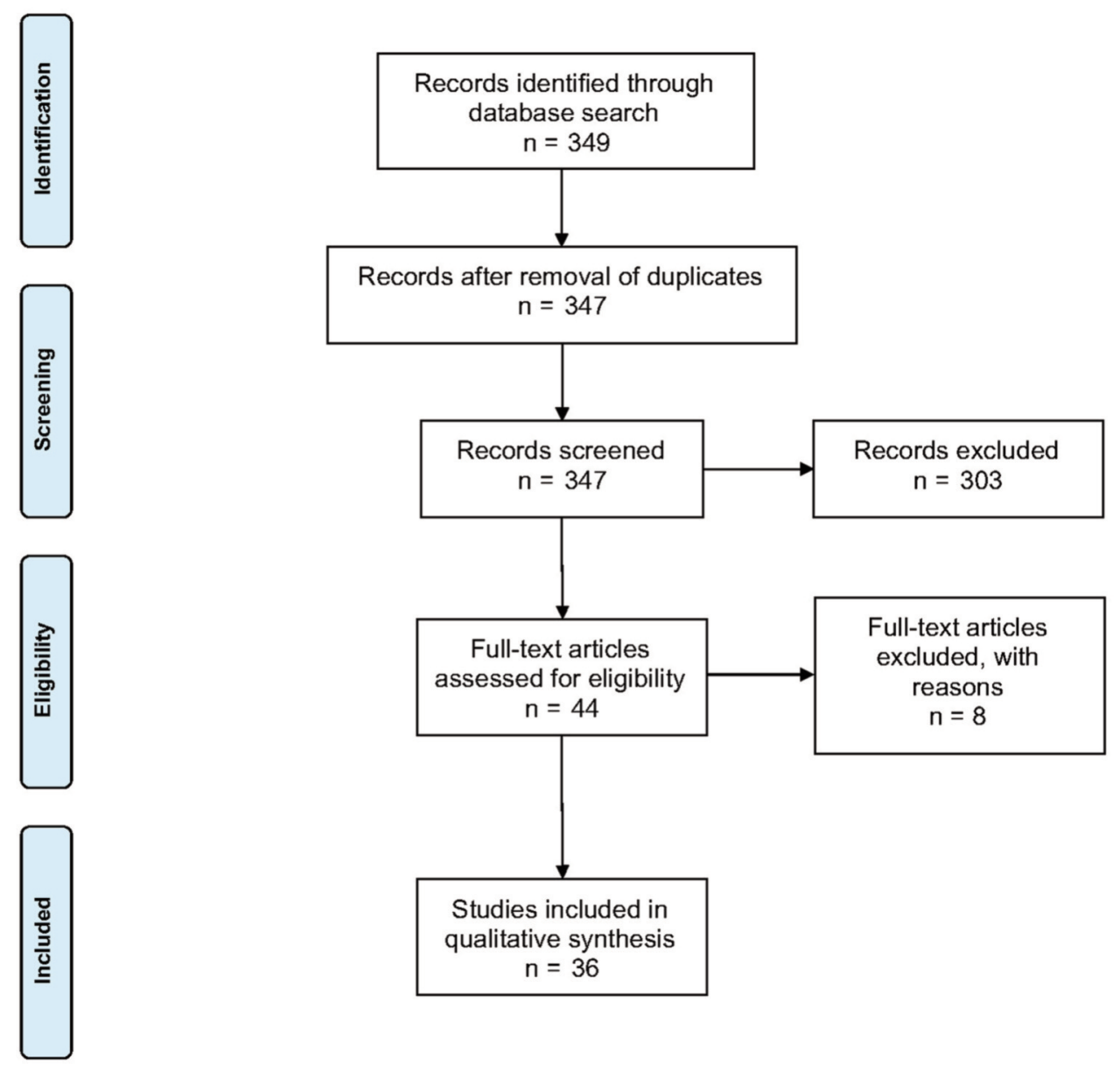

Figure 1. PRISMA flow chart showing study selection process.

conducted in accordance with the Preferred Reporting Items for Systematic Reviews and Meta-Analyses (PRISMA) guidelines (8). In light of the fact that the Covid-19 pandemic began less than a year ago, we considered retrospective studies, survey-based studies and observational studies as well as case series and letters. Two authors independently screened the published studies by title and abstract. All publications focusing on a comparison of the number of visits, surgeries or reasons for consultation before and during the pandemic in an orthopaedic or trauma center were included, regardless of the age of the study group. Inclusion was also possible by only indicating the change in percent. Furthermore, publications in English and German were included. No study was excluded on the basis of its country or the type of study.

\section{Results}

In total, 349 studies were identified. Based on the inclusion and exclusion criteria, 36 publications were found to be eligible for analysis. Most of the included studies were conducted in Europe $(n=25)$, followed by Asia $(n=5)$ and North America $(n=4)$. In addition, one study was from South
America $(n=1)$ and one from Australia $(n=1)$. The European studies came from Italy $(n=12)$, the UK $(n=5)$, Spain $(n=3)$, Belgium $(n=1)$, France $(n=1)$, Germany $(n=1)$, Ireland $(n=1)$ and Serbia $(n=1)$. The Asian studies were conducted in China $(n=2)$, India $(n=2)$ and Hong Kong $(n=1)$. Furthermore, three studies were performed in the United States of America $(n=3)$, whereas one North American study was from Mexico $(n=1)$. The remaining two trials were conducted in Brazil $(n=1)$ and Australia $(n=1)$. The literature selection process was conducted in accordance with the PRISMA guidelines (8) and is shown as a flow diagram in Figure 1. Table I presents detailed study characteristics of included publications.

Visits. Overall, 25 of the 36 included studies reported the number of visits, broken down for emergency or elective and total $(6,7,9-31)$. Sixteen studies (10-19, 25, 27-29, 31) described the change in total number of patient visits, whereby all 16 reported a decrease of between $20.9 \%$ and $90.1 \%$ during the Covid-19 pandemic $(10,12)$. The largest 
Table I. Detailed study characteristics of included publications.

\begin{tabular}{|c|c|c|c|c|c|c|}
\hline ID & Study & Year & Region & Country & Study type & LoE \\
\hline 1 & Gumina et al. (9) & 2020 & Europe & Italy & Retrospective study & 3 \\
\hline 2 & Rizzi et al. (10) & 2020 & North America & USA & Survey-based study & 4 \\
\hline 3 & Andrea et al. (11) & 2020 & Europe & Italy & Retrospective study & 3 \\
\hline 4 & Lubbe et al. (12) & 2020 & North America & USA & Retrospective study & 3 \\
\hline 5 & Dhillon et al. (13) & 2020 & Asia & India & Retrospective observational study & 3 \\
\hline 6 & Greenhalgh et al. (14) & 2020 & Europe & UK & Retrospective study & 3 \\
\hline 7 & Sugand et al. (15) & 2020 & Europe & UK & Retrospective study & 3 \\
\hline 8 & Andreata et al. (32) & 2020 & Europe & Italy & Retrospective study & 3 \\
\hline 9 & Luceri et al. (16) & 2020 & Europe & Italy & Retrospective study & 3 \\
\hline 10 & Staunton et al. (33) & 2020 & Europe & Ireland & Retrospective study & 3 \\
\hline 11 & Maryada et al. (17) & 2020 & Asia & India & Retrospective study & 3 \\
\hline 12 & Hua et al. (34) & 2020 & Asia & China & Retrospective study & 3 \\
\hline 13 & Yu et al. (18) & 2020 & Asia & China & Retrospective study & 3 \\
\hline 14 & Wong et al. (19) & 2020 & Australia & Australia & Retrospective cohort study & 3 \\
\hline 15 & ORCA Collaborative (20) & 2020 & Europe & UK & Survey-based study & 4 \\
\hline 16 & Espinosa-Uribe et al. (21) & 2020 & North America & Mexico & Letter to the editor & 5 \\
\hline 17 & Mitkovic et al. (42) & 2020 & Europe & Serbia & Retrospective study & 3 \\
\hline 18 & Ruggieri et al. (35) & 2020 & Europe & Italy & Retrospective study & 3 \\
\hline 19 & Druel et al. (36) & 2020 & Europe & France & Retrospective study & 3 \\
\hline 20 & Ohliger et al. (22) & 2020 & North America & USA & Retrospective study & 3 \\
\hline 21 & Wong et al. (23) & 2020 & Asia & Hong Kong & Retrospective cohort study & 3 \\
\hline 22 & Murphy et al. (37) & 2020 & Europe & UK & Retrospective study & 3 \\
\hline 23 & Ghermandi et al. (38) & 2020 & Europe & Italy & Retrospective observational study & 4 \\
\hline 24 & Benazzo et al. (6) & 2020 & Europe & Italy & Observational study & 3 \\
\hline 25 & Park et al. (24) & 2020 & Europe & UK & Longitudinal observational study & 3 \\
\hline 26 & Tamburrelli et al. (39) & 2020 & Europe & Italy & Retrospective study & 3 \\
\hline 27 & Lima et al. (25) & 2020 & South America & Brazil & Retrospective study & 3 \\
\hline 28 & Peiro-Garcia et al. (26) & 2020 & Europe & Spain & Retrospective observational study & 4 \\
\hline 29 & Dercks et al. (27) & 2020 & Europe & Germany & Retrospective study & 3 \\
\hline 30 & Luengo-Alonso et al. (28) & 2020 & Europe & Spain & Single-center cross-sectional study & 4 \\
\hline 31 & Giuntoli et al. (29) & 2020 & Europe & Italy & Retrospective study & 3 \\
\hline 32 & Hernigou et al. (40) & 2020 & Europe & Belgium & Retrospective observational study & 4 \\
\hline 33 & Zagra et al. (41) & 2020 & Europe & Italy & Retrospective study & 3 \\
\hline 34 & Gumina et al. (30) & 2020 & Europe & Italy & Case series & 4 \\
\hline 35 & Nunez et al. (7) & 2020 & Europe & Spain & Retrospective observational study & 4 \\
\hline 36 & Maniscalco et al. (31) & 2020 & Europe & Italy & Retrospective study & 3 \\
\hline
\end{tabular}

LoE: Level of evidence.

decrease in patient visits was reported by Rizzi et al. with the total number of visits dropping from 4,228 in January to 417 in April (10). From April to May, Rizzi et al. were able to offer a telemedicine conference as a phone or video call in 612 cases, after which $92.2 \%$ of the patients stated that they would participate in a telemedical conference call again (10). Furthermore, ten studies $(6,7,9,19,23-25,27,28,30)$ investigated the number of emergency and trauma visits, showing a decrease ranging between $37.7 \%$ and $74.2 \%$ (7, 19). Five studies provided information on the change in the number of elective visits $(6,19,20,25,27)$. The decrease in the number of elective visits ranged between $50.0 \%$ and $74.0 \%(6,19)$.

Surgery. A total of 23 studies presented a comparison of the number of performed orthopaedic and trauma surgeries $(6$,
$11-15,19,20,23-25,28,29,32-41)$. Of these 14 reported the total number of surgeries $(12,13,15,19,23,25,28,32$, $33,35,37-39,41)$. While most studies $(n=13)$ showed a decrease between $5.4 \%$ and $88.8 \%$ in the total number of surgeries, an increase of $47.8 \%$ was observed in one trial (38). Furthermore, performed trauma surgery decreased by $21.2 \%$ to $66.7 \%$ in 11 studies $(6,11,15,20,23-25,29,35$, $36,40)$. In contrast, three studies reported an increase of $32.1 \%$ to $94.2 \%$ in the number of trauma surgeries $(32,39$, $41)$. In addition, all nine studies reporting the number of elective surgeries showed a decrease ranging between $33.3 \%$ and $100 \%(6,14,20,23,25,29,35,39,41)$.

Reasons for consultation. Of the included studies 21 reported the change in the reasons for consultation $(6,7,11-13,15-$ 17, 22-24, 29-31, 36-40, 42). During the Covid-19 pandemic, 
there was a decrease of between $5.6 \%$ and $77.1 \%$ in polytraumas $(24,29)$. Additionally, consultations due to traffic accidents decreased by $26.4 \%$ to $88.9 \%(23,39)$. Moreover, sports injuries massively decreased by $59.3 \%$ to $100 \%(6,23)$. In contrast, eight studies described different changes in the number of domestic accidents $(6,11,17,23$, $29,31,36,39)$. While in five studies $(6,17,23,29,31)$ the number of domestic accidents decreased by $20 \%$ to $50 \%$, three studies reported an increase ranging between $22 \%$ and $300 \%(11,36,39)$. The total number of fractures decreased between $3.9 \%$ and $63.1 \%(17,40)$.

\section{Discussion}

Ever since the coronavirus spread throughout the world in early 2020, its impact on daily life has diminished only slightly. The objective of the present study was to analyze the current literature regarding the influence of the Covid-19 pandemic on orthopaedic and trauma surgery. Several studies from different countries reported on the impact of the pandemic by comparing pre-pandemic and pandemic data. We aimed to provide an overview of the influence on visits, surgeries and reasons for consultations in orthopaedic and trauma surgery during the Covid-19 pandemic.

The current literature shows a dramatic decline in nearly all aspects of orthopaedic and trauma surgery. The total number of patient visits as well as the number of emergency visits decreased by up to $90.1 \%$ and $74.2 \%$, respectively (10, $25)$. In comparison, a similar high decrease $(84.45 \%)$ was also observed in a multispecialty surgical emergency department in Italy (43). Many countries around the world have imposed quarantine and travel restrictions to slow the spread of infection and thereby ensure that the healthcare system does not collapse (7). Furthermore, the population was encouraged to stay home. This is also reflected in the reasons for consultations. Consequently, the number of traffic accidents decreased in some countries. For example, Nunez et al. reported a $78.6 \%$ reduction in traffic accident admissions at a tertiary trauma center in Spain (7). Other studies from Italy, the UK, India or the USA confirm these findings with similar data $(6,12,13,24)$. In addition, admissions due to sports injuries also decreased by up to $100 \%$ as team sports were prohibited in many countries (6). Reports on domestic accidents yielded different results (11, 29). While Giuntoli et al. reported a $57.2 \%$ decrease in domestic accidents, the number of domestic hand and wrist injuries tripled according to Andrea et al. $(11,29)$. It is important to remember that people spent more time at home because of government regulations, by the fear of possible exposure to Covid-19 might have kept people from seeking out a hospital. While there is no doubt that some injuries require immediate local treatment, telemedicine could be an option for providing safe and effective healthcare services in the outpatient setting (44). Rizzi et al. implemented telemedicine during the Covid-19 pandemic and conducted 612 orthopaedic telemedicine conferences between April and May 2020, whereby $92.2 \%$ of these patients said they would participate in such a conference again (10).

In view of the reduced number of emergency visits and cancelled elective procedures in some places, it does not seem surprising that the total number of surgeries performed also decreased in most hospitals (13, 25, 28). Paradoxically, Ghermandi et al. showed increased surgical activity at a department of oncology and spinal surgery in Italy, probably due to the fact that oncological spinal pathologies or degenerative disease with functional and neurological deficits cannot be postponed in the course of treatment (38). Even though the primary mode of transmission is respiratory tract shedding, several studies revealed that the virus was isolated in blood samples of patients infected with Covid-19 (45-47). It is well known that the use of power drills and saws, as common in orthopaedic and trauma surgery, is an aerosolgenerating procedure, resulting in a significant risk of the infection being transmitted to the theatre staff $(48,49)$. On the other hand, postponed surgeries lead to prolonged pain and possibly a worsening of the patient outcome $(50,51)$. Karikis et al. followed 71 patients over ten years and reported that patients who underwent a late anterior cruciate ligament reconstruction needed significantly more meniscectomies at index surgery and showed more osteoarthritis on the medial side of the knee ten years after reconstruction than did those with early reconstruction (50). Furthermore, after ten years Moosmayer et al. observed a significantly poorer outcome in patients with rotator cuff tears and delayed repair than in those who underwent early tendon repair (51). Strategies should therefore be developed to enable these patients to be treated promptly, even in the event of a continuing pandemic. At the same time, proper protection of the staff is required.

The primary limitations of this systematic literature review are the minimized exclusion criteria as well as the low level of evidence of included studies. In addition, most of the studies particularly refer to the first large wave of the Covid19 pandemic. As a result, the impact may appear overestimated in relation to the current situation. The main strength is the heterogeneous origin of the included literature, which gives a good overall view of the global impact had by the Covid-19 pandemic on orthopaedics and trauma surgery.

\section{Conclusion}

Although orthopaedics and trauma surgery does not appear to be in the front line of the pandemic, this specialty is clearly influenced by it. The majority reported a clear decrease in the number of cases in all areas examined. In the future, despite the pandemic, it will be important to maintain treatment and especially surgical care of patients in order to 
avoid negative effects on treatment progress. In addition, an analysis of the situation during the second wave at the end of 2020 should be attempted.

\section{Conflicts of Interest}

The Authors declare that there are no conflicts of interest.

\section{Authors' Contributions}

P. Blum: Literature research, data analysis, editing and writing of the article. D. Putzer: Data analysis and proofreading. M. Liebensteiner: co-editing and proofreading of the article. D. Dammerer: study protocol, study design, literature research, editing, writing and proofreading of the article. All Authors made pertinent contributions to the article, proofread and approved the final article before submission.

\section{Acknowledgements}

Professional language editing of the manuscript by Mary Margreiter is acknowledged.

\section{References}

1 Zhu N, Zhang D, Wang W, Li X, Yang B, Song J, Zhao X, Huang B, Shi W, Lu R, Niu P, Zhan F, Ma X, Wang D, Xu W, Wu G, Gao GF, Tan W and China Novel Coronavirus Investigating and Research Team.: A novel Coronavirus from patients with pneumonia in China, 2019. N Engl J Med 382(8): 727-733, 2020. PMID: 31978945. DOI: 10.1056/NEJMoa2001017

2 Timeline of WHO's response to Covid-19. Geneva, World Health Organization, 2020. Available at: https://www.who.int/ news/item/29-06-2020-covidtimeline [Last accessed on $15^{\text {th }}$ November 2020]

3 Coronavirus - Situation reports. Geneva, World Health Organization, 2020. Available at: https://www.who.int/docs/ default-source/coronaviruse/situation-reports/20201020-weeklyepi-update-10.pdf [Last accessed on 4th December 2020]

4 Angelico R, Trapani S, Manzia TM, Lombardini L, Tisone G and Cardillo M: The COVID-19 outbreak in Italy: Initial implications for organ transplantation programs. Am J Transplant 20(7): 1780-1784, 2020. PMID: 32243677. DOI: 10.1111/ajt. 15904

5 Suárez J, Mata E, Guerra A, Jiménez G, Montes M, Arias F, Ciga MA, Ursúa E, Ederra M, Arín B, Laiglesia M, Sanz A and Vera R: Impact of the COVID-19 pandemic during Spain's state of emergency on the diagnosis of colorectal cancer. J Surg Oncol 123(1): 32-36, 2021. PMID: 33078425. DOI: 10.1002/jso.26263

6 Benazzo F, Rossi SMP, Maniscalco P, Moretti B, Vaienti E, Ruggieri $\mathrm{P}$, Massè A, Medici A, Formica A, Di Maggio B, Caiaffa V, Mosconi M, Murena L, D'Angelo F, Belluati A, Mazza EL, Rivera F, Castelli A, Ghiara M, Rosolani M, Cioffi R, Pezzella R, Scaravilli G, Bove G, Stissi P, Mazzacane M, Quattrini F, Ciatti C, Trovarelli G, Pala E, Angelini A, Sanna F, Nonne D, Colombelli A, Raggini F, Puzzo A, Canton G, Maritan G, Iuliano A, Randelli P, Solarino G, Moretti L, Vicenti G, Garofalo N, Nappi V, Ripanti S, Chinni C, Pogliacomi F,
Visigalli A, Bini N, Aprato A and Perticarini L: The orthopaedic and traumatology scenario during Covid-19 outbreak in Italy: Chronicles of a silent war. Int Orthop 44(8): 1453-1459, 2020. PMID: 32591960. DOI: 10.1007/s00264-020-04637-3

7 Nuñez JH, Sallent A, Lakhani K, Guerra-Farfan E, Vidal N, Ekhtiari S and Minguell J: Impact of the COVID-19 Pandemic on an Emergency Traumatology Service: Experience at a tertiary trauma centre in Spain. Injury 51(7): 1414-1418, 2020. PMID: 32405089. DOI: 10.1016/j.injury.2020.05.016

8 Moher D, Liberati A, Tetzlaff J, Altman DG and PRISMA Group.: Preferred reporting items for systematic reviews and meta-analyses: the PRISMA statement. PLoS Med 6(7): e1000097, 2009. PMID: 19621072. DOI: 10.1371/journal.pmed. 1000097

9 Gumina S, Proietti R, Villani C, Carbone S and Candela V: The impact of COVID-19 on shoulder and elbow trauma in a skeletally immature population: An Italian survey. JSES Int 5(1): 3-8, 2021. PMID: 32984859. DOI: 10.1016/j.jseint.2020.08.003

10 Rizzi AM, Polachek WS, Dulas M, Strelzow JA and Hynes KK: The new 'normal': Rapid adoption of telemedicine in orthopaedics during the COVID-19 pandemic. Injury 51(12): 2816-2821, 2020. PMID: 32951916. DOI: 10.1016/j.injury. 2020.09.009

11 Poggetti A, Del Chiaro A, Nucci AM, Suardi C and Pfanner S: How hand and wrist trauma has changed during covid-19 emergency in Italy: Incidence and distribution of acute injuries. What to learn? J Clin Orthop Trauma 12(1): 22-26, 2021. PMID: 32921952. DOI: 10.1016/j.jcot.2020.08.008

12 Lubbe RJ, Miller J, Roehr CA, Allenback G, Nelson KE, Bear J and Kubiak EN: Effect of statewide social distancing and stayat-home directives on orthopaedic trauma at a southwestern level 1 trauma center during the COVID-19 pandemic. J Orthop Trauma 34(9): e343-e348, 2020. PMID: 32815849. DOI: 10.1097/BOT.0000000000001890

13 Dhillon MS, Kumar D, Saini UC, Bhayana H, Gopinathan NR and Aggarwal S: Changing pattern of orthopaedic trauma admissions during COVID-19 pandemic: Experience at a tertiary trauma centre in India. Indian J Orthop: 1-6, 2020. PMID: 32873987. DOI: $10.1007 / \mathrm{s} 43465-020-00241-0$

14 Greenhalgh M, Dupley L, Unsworth R and Boden R: Where did all the trauma go? A rapid review of the demands on orthopaedic services at a UK Major Trauma Centre during the COVID-19 pandemic. Int J Clin Pract: e13690, 2020. PMID: 32852851. DOI: $10.1111 /$ ijcp.13690

15 Sugand K, Park C, Morgan C, Dyke R, Aframian A, Hulme A, Evans S, Sarraf KM, Baker C, Bennett-Brown K, Simon H, Bray E, Li L, Lee N, Pakroo N, Rahman K and Harrison A: Impact of the COVID-19 pandemic on paediatric orthopaedic trauma workload in central London: A multi-centre longitudinal observational study over the "golden weeks". Acta Orthop 91(6): 633-638, 2020. PMID: 32835573. DOI: 10.1080/17453674. 2020.1807092

16 Luceri F, Morelli I, Accetta R, Mangiavini L, Maffulli N and Peretti GM: Italy and COVID-19: The changing patient flow in an orthopedic trauma center emergency department. J Orthop Surg Res 15(1): 323, 2020. PMID: 32795347. DOI: 10.1186/ s13018-020-01816-1

17 Maryada VR, Mulpur P, Guravareddy AV, Pedamallu SK and Vijay Bhasker B: Impact of COVID-19 Pandemic on Orthopaedic Trauma Volumes: a Multi-Centre Perspective From 
the state of Telangana. Indian J Orthop: 1-6, 2020. PMID: 32836367. DOI: $10.1007 / \mathrm{s} 43465-020-00226-\mathrm{z}$

18 Yu P, Wu C, Zhuang C, Ye T, Zhang Y, Liu J and Wang L: The patterns and management of fracture patients under COVID-19 outbreak in China. Ann Transl Med 8(15): 932, 2020. PMID: 32953732. DOI: $10.21037 / \mathrm{atm}-20-4174$

19 Wong FL, Antoniou G, Williams N and Cundy PJ: Disruption of paediatric orthopaedic hospital services due to the COVID-19 pandemic in a region with minimal COVID-19 illness. J Child Orthop 14(4): 245-251, 2020. PMID: 32874355. DOI: 10.1302/1863-2548.14.200140

20 ORCA Collaborative (Orthopaedic Research Collaborative East Anglia). Electronic address: orca@eoeortho.com. and ORCA Collaborative (Orthopaedic Research Collaborative East Anglia).: The response of Trauma \& Orthopaedic Departments to the first four weeks of lockdown for the COVID-19 pandemic - A trainee-led analysis of the East of England. Surgeon 19(1): e14-e19, 2021. PMID: 32830040. DOI: 10.1016/j.surge. 2020.07.007

21 Espinosa-Uribe AG, Gonzalez-Saldivar JC, Valverde-Galindo LA, Meza-Flores J and Gutiérrez-de la O J: Regarding "The orthopaedic and traumatology scenario during Covid-19 outbreak in Italy: Chronicles of a silent war" a Mexican perspective. Int Orthop 44(10): 2187-2188, 2020. PMID: 32737519. DOI: $10.1007 / \mathrm{s} 00264-020-04751-2$

22 Ohliger E, Umpierrez E, Buehler L, Ohliger AW, Magister S, Vallier H and Hirschfeld AG: Mental health of orthopaedic trauma patients during the 2020 COVID-19 pandemic. Int Orthop 44(10): 1921-1925, 2020. PMID: 32676778. DOI: 10.1007/s00264-020-04711-w

23 Wong JSH and Cheung KMC: Impact of COVID-19 on orthopaedic and trauma service: An epidemiological study. J Bone Joint Surg Am 102(14): e80, 2020. PMID: 32675668. DOI: 10.2106/JBJS.20.00775

24 Park C, Sugand K, Nathwani D, Bhattacharya R and Sarraf KM: Impact of the COVID-19 pandemic on orthopedic trauma workload in a London level 1 trauma center: The "golden month". Acta Orthop 91(5): 556-561, 2020. PMID: 32573331. DOI: $10.1080 / 17453674.2020 .1783621$

25 Lima EBS, Belangero PS, Falótico GG, Mansur NSB, Luzo MVM and Reis FBD: Intervention protocol of the orthopedics and traumatology department of a high-complexity university hospital to cope with the COVID-19 pandemic. Rev Bras Ortop (Sao Paulo) 55(3): 269-277, 2020. PMID: 32616970. DOI: 10.1055/s-0040-1712972

26 Peiro-Garcia A, Corominas L, Coelho A, DeSena-DeCabo L, Torner-Rubies $\mathrm{F}$ and Fontecha CG: How the COVID-19 pandemic is affecting paediatric orthopaedics practice: A preliminary report. J Child Orthop 14(3): 154-160, 2020. PMID: 32582381. DOI: 10.1302/1863-2548.14.200099

27 von Dercks N, Körner C, Heyde CE and Theopold J: [How badly is the coronavirus pandemic affecting orthopaedic and trauma surgery clinics?: An analysis of the first 5 weeks]. Orthopade 49(6): 494-501, 2020. PMID: 32436038. DOI: 10.1007/s00132-020-03926-4

28 Luengo-Alonso G, Pérez-Tabernero FG, Tovar-Bazaga M, Arguello-Cuenca JM and Calvo E: Critical adjustments in a department of orthopaedics through the COVID-19 pandemic. Int Orthop 44(8): 1557-1564, 2020. PMID: 32474718. DOI: $10.1007 / \mathrm{s} 00264-020-04647-1$
29 Giuntoli M, Bonicoli E, Bugelli G, Valesini M, Manca M and Scaglione M: Lessons learnt from COVID 19: An Italian multicentric epidemiological study of orthopaedic and trauma services. J Clin Orthop Trauma 11(4): 721-727, 2020. PMID: 32684717. DOI: $10.1016 /$ j.jcot.2020.05.021

30 Gumina S, Proietti R, Polizzotti G, Carbone S and Candela V: The impact of COVID-19 on shoulder and elbow trauma: An Italian survey. J Shoulder Elbow Surg 29(9): 1737-1742, 2020. PMID: 32713663. DOI: 10.1016/j.jse.2020.05.003

31 Maniscalco P, Poggiali E, Quattrini F, Ciatti C, Magnacavallo A, Vercelli A, Domenichini M, Vaienti E, Pogliacomi F and Ceccarelli F: Proximal femur fractures in COVID-19 emergency: The experience of two Orthopedics and Traumatology departments in the first eight weeks of the Italian epidemic. Acta Biomed 91(2): 89-96, 2020. PMID: 32420932. DOI: 10.23750/abm.v91i2.9636

32 Andreata M, Faraldi M, Bucci E, Lombardi G and Zagra L: Operating room efficiency and timing during coronavirus disease 2019 outbreak in a referral orthopaedic hospital in Northern Italy. Int Orthop 44(12): 2499-2504, 2020. PMID: 32803358. DOI: $10.1007 / \mathrm{s} 00264-020-04772-\mathrm{x}$

33 Staunton P, Gibbons JP, Keogh P, Curtin P, Cashman JP and O'Byrne JM: Regional trauma patterns during the COVID-19 pandemic. Surgeon: 2020. PMID: 32893129. DOI: 10.1016/ j.surge.2020.08.003

34 Hua W, Zhang Y, Wu X, Gao Y and Yang C: Work characteristics of orthopaedic surgeons during the COVID-19 pandemic: A single center analysis. Perioper Care Oper Room Manag 20: 100127, 2020. PMID: 32835118. DOI: 10.1016/j.pcorm.2020.100127

35 Ruggieri P, Trovarelli G, Angelini A, Pala E, Berizzi A and Donato D: COVID-19 strategy in organizing and planning orthopedic surgery in a major orthopedic referral center in an area of Italy severely affected by the pandemic: Experience of the department of Orthopedics, university of Padova. J Orthop Surg Res 15(1): 279, 2020. PMID: 32703305. DOI: 10.1186/ s13018-020-01740-4

36 Druel T, Andeol Q, Rongieras F, Bertani A, Bordes M and Alvernhe A: Evaluation of containment measures' effect on orthopaedic trauma surgery during the COVID-19 pandemic: A retrospective comparison between 2019 and 2020. Int Orthop 44(11): 2229-2234, 2020. PMID: 32696333. DOI: 10.1007/ s00264-020-04712-9

37 Murphy T, Akehurst $\mathrm{H}$ and Mutimer J: Impact of the 2020 COVID-19 pandemic on the workload of the orthopaedic service in a busy UK district general hospital. Injury 51(10): 2142-2147, 2020. PMID: 32654849. DOI: 10.1016/j.injury.2020.07.001

38 Ghermandi R, Pipola V, Terzi S, Tedesco G, Cavallari C, Bandiera S, Barbanti Bròdano G, Evangelisti G, Girolami M and Gasbarrini A: The impact of SARS-CoV-2 pandemic on oncologic and degenerative spine surgery department activity: The experience of Rizzoli orthopaedic institute under COVID19 lockdown. Eur Rev Med Pharmacol Sci 24(13): 7519-7523, 2020. PMID: 32706094. DOI: 10.26355/eurrev_202007_21926

39 Tamburrelli FC, Meluzio MC, Perna A, Santagada DA, Genitiempo M, Zirio G and Proietti L: Spinal surgery in COVID-19 pandemic era: One trauma hub center experience in central-southern Italy. J Orthop 22: 291-293, 2020. PMID: 32616990. DOI: 10.1016/j.jor.2020.06.014

40 Hernigou J, Morel X, Callewier A, Bath O and Hernigou P: Staying home during "COVID-19" decreased fractures, but 
trauma did not quarantine in one hundred and twelve adults and twenty eight children and the "tsunami of recommendations" could not lockdown twelve elective operations. Int Orthop 44(8): 1473-1480, 2020. PMID: 32451655. DOI: 10.1007/s00264-02004619-5

41 Zagra L, Faraldi M, Pregliasco F, Vinci A, Lombardi G, Ottaiano I, Accetta R, Perazzo P and D'Apolito R: Changes of clinical activities in an orthopaedic institute in North Italy during the spread of COVID-19 pandemic: A seven-week observational analysis. Int Orthop 44(8): 1591-1598, 2020. PMID: 32449043. DOI: $10.1007 / \mathrm{s} 00264-020-04590-1$

42 Mitkovic MM, Bumbasirevic M, Milenkovic S, Gajdobranski D, Bumbasirevic V and Mitkovic MB: Influence of coronavirus disease 2019 pandemic state of emergency in orthopaedic fracture surgical treatment. Int Orthop: 2020. PMID: 32728928. DOI: $10.1007 / \mathrm{s} 00264-020-04750-3$

43 Vanni G, Legramante JM, Pellicciaro M, DE Carolis G, Cotesta M, Materazzo M, Buonomo C, Farinaccio A, Santori F, Saraceno F, Ielpo B, Aiello F, Paganelli C, Grande M, DE Andreis G, Chiocchi M, Palombi L and Buonomo OC: Effect of lockdown in surgical emergency accesses: Experience of a COVID-19 hospital. In Vivo 34(5): 3033-3038, 2020. PMID: 32871849. DOI: 10.21873 /invivo.12137

44 Sood S, Mbarika V, Jugoo S, Dookhy R, Doarn CR, Prakash N and Merrell RC: What is telemedicine? A collection of 104 peerreviewed perspectives and theoretical underpinnings. Telemed $\mathbf{J}$ E Health 13(5): 573-590, 2007. PMID: 17999619. DOI: $10.1089 / \mathrm{tmj} .2006 .0073$

45 Wang $\mathrm{W}, \mathrm{Xu} \mathrm{Y}$, Gao R, Lu R, Han K, Wu G and Tan W: Detection of SARS-CoV-2 in Different Types of Clinical Specimens. JAMA 323(18): 1843-1844, 2020. PMID: 32159775. DOI: 10.1001 /jama.2020.3786

46 Zhang W, Du RH, Li B, Zheng XS, Yang XL, Hu B, Wang YY, Xiao GF, Yan B, Shi ZL and Zhou P: Molecular and serological investigation of 2019-nCoV infected patients: Implication of multiple shedding routes. Emerg Microbes Infect 9(1): 386-389, 2020. PMID: 32065057. DOI: 10.1080/22221751.2020.1729071
47 Huang C, Wang Y, Li X, Ren L, Zhao J, Hu Y, Zhang L, Fan G, Xu J, Gu X, Cheng Z, Yu T, Xia J, Wei Y, Wu W, Xie X, Yin W, Li H, Liu M, Xiao Y, Gao H, Guo L, Xie J, Wang G, Jiang R, Gao Z, Jin Q, Wang J and Cao B: Clinical features of patients infected with 2019 novel coronavirus in Wuhan, China. Lancet 395(10223): 497-506, 2020. PMID: 31986264. DOI: 10.1016/ S0140-6736(20)30183-5

48 Sobti A, Fathi M, Mokhtar MA, Mahana K, Rashid MS, Polyzois I, Narvani AA and Imam MA: Aerosol generating procedures in trauma and orthopaedics in the era of the Covid19 pandemic; What do we know? Surgeon: 2020. PMID: 32883580. DOI: $10.1016 /$ j.surge.2020.08.001

49 Geevarughese NM and Haq RU: Aerosol generating procedures in orthopaedics and recommended protective gear. J Clin Orthop Trauma 12(1): 40-42, 2021. PMID: 32863676. DOI: 10.1016/ j.jcot.2020.08.019

50 Karikis I, Åhlén M, Sernert N, Ejerhed L, Rostgård-Christensen L and Kartus J: The Long-Term Outcome After Early and Late Anterior Cruciate Ligament Reconstruction. Arthroscopy 34(6): 1907-1917, 2018. PMID: 29523374. DOI: 10.1016/j.arthro. 2018.01.026

51 Moosmayer S, Lund G, Seljom US, Haldorsen B, Svege IC, Hennig T, Pripp AH and Smith HJ: At a 10-year follow-up, tendon repair is superior to physiotherapy in the treatment of small and medium-sized rotator cuff tears. J Bone Joint Surg Am 101(12): 1050-1060, 2019. PMID: 31220021. DOI: 10.2106/ JBJS.18.01373
Received January 27, 2021

Revised February 15, 2021

Accepted February 18, 2021 